\title{
ACESSO À SAÚDE PELAS TRAVESTIS NO BRASIL
}

\author{
Nathália Ferreira Santos Tost ${ }^{1}$ \\ Dalvani Marques \\ ${ }^{\top}$ Aluna de graduação em Enfermagem pela Faculdade de Enfermagem da Universidade \\ Estadual de Campinas (UNICAMP)
}

Introdução: O homem é constituído a partir dos significados que atribui ou the são atribuídos. A travesti, figura ambivalente, confronta o binarismo de gênero de modo a adequar o corpo com a construção de sua identidade pessoal, flertando com o sem-sentido, de forma a ser posta a margem da sociedade binária. Questiona-se, então, como a marginalização da construção corporal da travesti influenciaria no acesso dessa população à saúde. Objetivo: Identificar a construção da corporeidade travesti e o acesso dessa população aos serviços públicos de saúde na literatura científica nacional. Método: Trata-se de uma revisão integrativa. A coleta de dados foi realizada através do portal de pesquisa em saúde BVS (Biblioteca Virtual em Saúde), utilizando os descritores: travestismo, pessoas transgênero e saúde das minorias. Como critério de inclusão consideraram-se apenas artigos publicados entre os anos de 2010 e 2017, disponíveis na íntegra online e que abordavam como sujeitos de pesquisa: trabalhadores da saúde ou travestis. A análise do material baseou-se na Análise de Conteúdo, modalidade Análise Temática. Resultados e Discussão: Foram analisados 14 artigos, cujos resultados delinearam três categorias: Corpo Travesti - aborda questões sobre a construção e o reconhecimento dos corpos, a aquisição de uma nova identidade através de intervenções permanentes, tendo a dor como um eixo transversal; Acesso aos serviços de saúde - evidenciando que as Unidades Básicas de Saúde não constituem porta de entrada na assistência e que os profissionais se encontram desarmados para atender a construção travesti; e Rede de Apoio - forma de reestruturação da rede a fim da busca pela integralidade no cuidado, da visão do usuário como ser integral, focando-se em práticas de prevenção de agravos e proteção à saúde dessa população. Considerações finais: A dualidade do corpo travesti, lida pela sociedade como inadequada, é fator determinante para a exclusão, compreendida pelas travestis como algo imutável, afastando-as da luta pelos seus direitos. A constituição de uma rede de apoio, o fortalecimento 
de políticas públicas, a participação social e a ocupação de espaços, nos quais são desvalorizadas, são caminhos para promover o acesso às demandas específicas das travestis.

Palavras-chave: Travestismo. Pessoas transgênero. Saúde das minorias.

\section{Referências}

Souza MHT et al. Itinerários terapêuticos de travestis da região central do Rio Grande do Sul, Brasil. Ciência \& Saúde Coletiva. 2014; 19(7): 2277-2286.

Antunes PPS, Mercadante EF. Transgender, aging and old age - Do transgender people get old?.Revista Temática Kairós Gerontologia. 2013; 16(1):69-93.

Amorim SMG, Vieira FS, Brancaleoni AP. Percepções acerca da condição de vida e vulnerabilidade à saúde de travestis. Saúde em Debate. 2013; 37(98): 525-535.

Sehnem GD, Rodrigues RL, Lipinski JM et al. Assistência em Saúde às Travestis na Atenção Primária: do acesso ao atendimento. Rev Enferm UFPE. 2017; 11(4): 1676-1684.

Campos, CJG. Método de análise de conteúdo: ferramenta para a análise de dados qualitativos no campo da saúde. Rev Bras Enferm. 2004; 57(5): 611-614. 